\title{
Ação coletiva passiva: considerações acerca de sua viabilidade no ordenamento jurídico brasileiro*
}

\section{Passive class actions: considerations about their viability in brazilian law}

Thiago Ferrare Pinto'

\section{Resumo}

O presente artigo tem por fim analisar a possibilidade de adoção da ação coletiva passiva pelo ordenamento jurídico brasileiro. Partindo de duas ideias centrais à compreensão do atual estágio de evolução da prática do direito - as gerações dos direitos e a instrumentalidade do processo - e através da comparação do modelo brasileiro com o adotado nos Estados Unidos da América, analisa-se, em primeiro lugar, as notas distintivas de tal instituto jurídico e, em seguida, busca-se construir um argumento apto a sustentar a compatibilidade das ações coletivas passivas com a dogmática processual brasileira. Tal argumento parte de algumas conquistas sedimentadas da teoria contemporânea do direito, tais como a ideia de força normativa da Constituição e a sua consequente centralidade na ordem jurídica, chegando à conclusão necessária de que a adoção da modalidade passiva das ações coletivas, para além de uma mera possibilidade, surge como verdadeiro imperativo.

Palavras-chave: Direito processual. Ação coletiva passiva. Constitucionalização. Instrumentalidade do Processo.

\begin{abstract}
This paper's objective is to analyze the possibilities of defendant class actions usage in the Brazilian legal order. Based on two central ideas of the current stage of law's practice - the right's generations and the process's instrumentality - and through comparison between the Brazilian and American models, it was analyzed, at first, the distinctive notations of this legal institute. Next, we intent to build an argument that will support the compatibility of the defendant class actions with the Brazilian process. This argument goes from some solid conquests in contemporary theory of law, such as the ideas of normative force of the Constitution and its subsequent central role in the legal order and get to the necessary conclusion that the adoption of the defendant class actions, in addition to a mere possibility, emerge as a real imperative.
\end{abstract}

Keywords: Process law. Defendant class action. Constitution. Process instrumentality.

* Recebido em: dezembro de 2011. Aprovado em: março de 2012.

1 Graduando do curso de Direito do Centro Universitário de Brasília - UniCEUB. Membro do Grupo de Estudo e Pesquisa em Políticas Públicas Sociais no Distrito Federal - GEPPPSDF do UniCEUB, e do grupo Análise Crítica e Reconstrução Histórica da Assembleia Nacional Constituinte de 1987 do Instituto Brasiliense de Direito Público - IDP. 


\section{Introdução}

Desde meados do século XX, o Direito Processual vem passando por grandes transformações. A principal delas - e que será tratada mais de perto neste trabalho diz respeito ao desabrochar do Direito Processual coletivo. Com efeito, percebeu-se que as concepções tradicionais que permeavam o processo não se faziam suficientes para a resolução de novos problemas que vinham surgindo no seio da sociedade. Assim, como se mostrará adiante, o processo coletivo surge como instrumento - e tal concepção instrumental, como também se verá, é algo recente - para a efetivação de novas categorias de direitos que se apresentaram no decorrer do século passado.

É nesse contexto que se revela a grande importância de um estudo aprofundado a respeito da ação coletiva passiva. Consiste ela, basicamente, na possibilidade de que figurem coletividades no polo passivo de qualquer ação coletiva. A despeito da aparente simplicidade da matéria, ela guarda minúcias que nos impõem grandes desafios teóricos, conforme se verá.

Buscar-se-á demonstrar, em primeiro lugar, a possibilidade de harmonização da ação coletiva passiva com as noções processuais tradicionais, em especial com as ideias de legitimidade e coisa julgada. Nesse ponto, serão feitas algumas considerações a respeito das class actions norte-americanas, de modo a apurar a viabilidade de serem incorporados ao nosso ordenamento algumas das ideias que por lá vigoram.

Na mesma linha de pensamento, será elaborado passo a passo um argumento capaz de fundamentar a exigência de aceitação das ações coletivas passivas no direito brasileiro. Tal argumento partirá de algumas das ideias mais valiosas para a teoria jurídica contemporânea - e, em especial, para a teoria constitucional contemporânea -, e buscará atestar a compatibilidade dessa exigência com os mais caros princípios de nosso ordenamento.

Naturalmente, todo o raciocínio que aqui será elaborado não tem a pretensão de dar fim às grandes polêmicas que circundam a matéria. Pelo contrário, tendo ciência da complexidade teórica e prática envolvida na questão, o que se busca é prestar uma contribuição ao estudo da ação coletiva passiva, visto que a utilidade prática e a relevância teórica do tema tem sido, tanto no âmbito doutrinário como no judicial, menosprezada.

\section{Duas premissas}

\subsection{As gerações/dimensões dos direitos}

Usualmente se diz que são três as gerações - ou dimensões - dos direitos. Tal classificação, à medida que narra uma linha de evolução na concepção das prerrogativas juridicamente exigíveis, faz-se extremamente relevante para a matéria em estudo. Vejamos quais são, em linhas gerais, as principais características de cada uma dessas espécies de direitos.

Os direitos de primeira geração são aqueles que, constituindo uma esfera de poderes titularizados exclusivamente pelo indivíduo, limitam a atividade do Estado. São exemplos clássicos: liberdade de expressão e liberdade de locomoção, dentre outros. Tais direitos exigem uma atividade omissiva - um non facere - dos titulares do poder político. Essas prerrogativas têm seu surgimento relacionado às revoluções liberais do final do século XVIII. De fato, nesse momento histórico, buscou-se suplantar os abusos cometidos pelo Estado Absolutista, e tal se deu por meio da criação de óbices, ou seja, de barreiras para além das quais o Estado não poderia agir.

Já os direitos de segunda geração possuem características bastante diferentes. Visando alcançar uma igualdade não meramente formal entre os cidadãos, tais direitos exigem uma atividade comissiva do Estado, ou seja, exigem que o governo atue ativamente na distribuição dos recursos da sociedade. Os direitos à saúde e ao trabalho são os mais significativos exemplos. O aparecimento dessa categoria de direitos é consequência da Revolução Industrial que, tendo surgido na Inglaterra durante o século XVIII, alastrou-se pelo mundo nos séculos seguintes. Como se sabe, nesse período, a humanidade viu-se diante de novas ameaças à liberdade dos indivíduos; ameaças essas que não poderiam ser afastadas com medidas baseadas no individualismo liberal já superado. É nesse contexto que surgem os direitos de segunda geração, também chamados, pelas razões citadas, de direitos sociais.

No dizer de Bobbio, "[...] ao lado dos direitos sociais [...] emergiram ho2je os chamados direitos de terceira geração, que constituem uma categoria, para dizer a verdade, ainda excessivamente heterogênea e vaga, o que nos impede de compreender do que efetivamente se trata".

2 BOBBIO, Norberto. A era dos direitos. Trad. de Carlos Nelson Coutinho. Rio de Janeiro: Campus, 1992. p. 6. 
A despeito de tal vagueza, pode-se dizer que tais direitos se caracterizam pelo fato de não serem titularizados por nenhum indivíduo enquanto ser isolado. Ou seja, eles estabelecem prerrogativas que não podem ser claramente individualizadas na medida em que não dizem respeito a qualquer cidadão em particular. Exemplos usuais são o direito a um meio ambiente equilibrado, o direito à paz $\mathrm{e}$, segundo alguns, os direitos dos consumidores. ${ }^{3}$

No mais, não se buscará aqui investigar a quais dessas categorias pertencem os direitos tuteláveis por via de ação coletiva, já que, além de não haver consenso sobre essa matéria, ${ }^{4}$ tal intento não teria qualquer utilidade prática. O que se quer aqui ressaltar - e é esse o propósito deste item - é que o tema dos direitos coletivos e difusos e, portanto, o estudo do processo coletivo somente se torna relevante no momento em que se passa a conceber e aceitar a existência de direitos que não estão ligados unicamente aos indivíduos enquanto seres isolados; direitos que, nesse sentido, não podem ser plenamente efetivados por meio do processo tradicionalmente individual.

\subsection{A instrumentalização do processo}

Outra ideia relevante para a compreensão da forma como se tratará o objeto do presente trabalho é a instrumentalidade do processo. Vejamos, de forma contextualizada, em que ela consiste.

"A história do direito processual inclui três fases metodológicas fundamentais". ${ }^{5} \mathrm{Na}$ primeira delas, que durou até meados do século XIX, a ação era concebida como uma dimensão do direito material, ou seja, o "direito" de ação era o próprio direito material sendo defendido em juízo. Durante esse período, por razões diversas, elementos hoje tidos como fundamentais para o direito processual - tais como a ideia de ação e processo, por exemplo - estavam de tal forma imbricados ao direito material, que não despertavam qualquer atenção enquanto objetos autônomos de estudo.

A segunda fase é comumente denominada autonomista. Pode-se dizer que foi nesse período que o di-

3 BOBBIO, Norberto. A era dos direitos. Trad. de Carlos Nelson Coutinho. Rio de Janeiro: Campus, 1992.

4 BENJAMIN, Antônio Herman V.; MARQUES, Claudia Lima; BESSA, Leonardo Roscoe. Manual de direito do consumidor. São Paulo: Revista dos Tribunais, 2010. p. 430-460.

5 CINTRA Antonio Carlos de Araújo et al. Teoria geral do processo. São Paulo: Malheiros, 2008. p. 48. reito processual passou a ser visto como um ramo independente na ciência jurídica. Aliás, "a afirmação da autonomia científica do direito processual foi uma grande preocupação desse período"6 $\mathrm{o}$ que explica o fato de terem se desenvolvido, nesse momento da história, os mais relevantes conceitos que até os dias de hoje são utilizados no âmbito do direito processual.

Ocorre que tais ideias acarretaram um sensível isolamento do Direito Processual em relação ao direito material. A esse respeito, parece relevante a seguinte passagem:

Faltou, na segunda fase, uma postura crítica. O sistema processual era estudado mediante uma visão puramente introspectiva, no exame de seus institutos, de suas categorias e conceitos fundamentais; e visto o processo costumeiramente como mero instrumento técnico predisposto à realização da ordem jurídica material, sem o reconhecimento de suas conotações deontológicas e sem a análise dos seus resultados na vida das pessoas ou preocupação pela justiça que ele fosse capaz de fazer. ${ }^{7}$

Por fim, chega-se à terceira fase, a instrumentalista. Nesse período, dá-se a "[...] conscientização de que a importância do processo está em seus resultados". $\mathrm{O}$ processo passa a ser visto como um instrumento à concretização do direito material. Instrumento, porém, não apenas no sentido formal, mas também no sentido substancial, ou seja, passa-se a aceitar a ideia de que o processo, à medida que se presta a dar efetividade ao direito material, também se contamina com os valores deste; serve, portanto, como um "instrumento ético".

\subsection{Fusão das duas ideias}

Conforme se buscou demonstrar, o direito material, no percurso de suas diversas gerações, passou por mudanças significativas; mudanças essas que, ressalte-se, colocaram em cheque as ideias tradicionais do direito processual. Ante tal fato, e dado o pressuposto acima aludido, de que o processo deve servir de instrumento à efetivação do direito material, faz-se necessária a investigação de novas ferramentas capazes de auxiliar o operador jurídico no trato desses novos desafios.

6 CINTRA, Antonio Carlos de Araújo; GRINOVER, Ada Pellegrini; DINAMARCO, Cândido Rangel. Teoria geral do processo. 24. ed. São Paulo: Malheiros, 2008. p. 48.

7 Ibidem, p. 48-49.

8 BEDAQUE, José Roberto dos Santos. Direito e processo. São Paulo: Malheiros, 2009. p. 17.

9 Ibidem, p. 22. 
É nesse sentido que se mostra relevante o estudo, não apenas da ação coletiva passiva, mas do processo coletivo como um todo. Com efeito, como meio de superação das ortodoxas ideias individualistas que dominam o estudo e a prática do processo, tais matérias surgem como um campo fértil para a releitura de velhas e para o desenvolvimento de novas ideias

\section{Principais aspectos processuais}

\subsection{Legitimidade e as ações coletivas passivas}

\subsubsection{Modelo brasileiro de aferição da legitimidade ativa nas ações coletivas}

Conforme dispõe o inciso VI do art. 267 do Código de Processo Civil, a aferição do mérito de qualquer demanda judicial está condicionada à existência do que se convencionou chamar de condições da ação. São elas três: o interesse de agir, a possibilidade jurídica do pedido e a legitimidade para a causa. Interessa-nos esta última.

A legitimidade ad causam possui duas modalidades. São elas: a legitimidade ordinária e a extraordinária. $\mathrm{Na}$ legitimidade ordinária, há uma coincidência entre o titular da relação jurídica material e aquele que figura na relação processual. Como o próprio nome está a indicar, esse tipo de legitimação é o mais comum. Já na legitimação extraordinária - também designada como substituição processual - ocorre que aquele que figura na relação processual não é o titular do direito material, o que é o mesmo que dizer que ele atua no processo em nome próprio na defesa de interesse alheio.

A legitimação extraordinária, pelas peculiaridades referidas, sofre certas restrições. A principal delas é a prevista no artigo $6^{\circ}$ do Código de Processo Civil, in verbis: "Ninguém poderá pleitear, em nome próprio, direito alheio, salvo quando autorizado por lei"

Segundo a doutrina majoritária, a legitimidade ativa para as ações coletivas é extraordinária. Isso quer dizer que ela estaria sujeita à restrição legal acima referida. Assim sendo, salvo em algumas situações de pequena significância - tais como a prevista no artigo $82, \$ 1^{\circ}$ do Código de Defesa do Consumidor - a legitimidade tem como requisito apenas a expressa previsão legal.

Ademais, é isso que se extrai de breve análise dos diplomas normativos que regulam a matéria, em especial da Lei da Ação Civil Pública, no 7.347/85 e do Código de Defesa do Consumidor, Lei no 8.078/90. Tal observação apenas confirma que, para além daqueles casos expressamente previstos, não se afigura possível a participação de entes coletivos no polo ativo das demandas coletivas.

\subsubsection{O modelo dos EUA para a legitimação coletiva: a representação adequada}

No sistema jurídico dos EUA tem grande relevância o direito processual coletivo. Pode-se dizer com certa segurança que grande parte das nações que passaram a regular tais demandas o fizeram por influência dos norteamericanos. Lá se admite não somente a ação coletiva ativa, mas também a passiva, designada como defendant class action. Ocorre que, como se buscará mostrar, há uma significativa diferença entre esse modelo e o que vigora no Brasil. Veremos neste tópico quais são essas diferenças no que diz respeito ao regramento da legitimidade para tais ações.

Conforme se buscou demonstrar no item anterior, no Brasil, ao menos em relação à legitimidade ativa para as ações coletivas, vigora o modelo ope legis, ou seja, a aferição da legitimidade dá-se pelo exame unicamente da lei. Coisa diversa se observa na sistemática processual dos EUA. Com efeito, observa-se, em primeiro lugar, que no regramento das class actions não se estabeleceu qualquer diferença entre os requisitos da legitimação ativa e os da passiva. Ou seja, as mesmas regras se aplicam a ambas as modalidades, conforme se extrai da Rule 23, das Federal Rules of Civil Procedure, de 1966.

O que nos parece mais relevante no sistema norteamericano é a ideia de "representação adequada". De fato, é esse o principal requisito para a legitimidade nas class actions. Mas em que consiste a adequacy of representation? Em linhas gerais, ela exige que aquele que atua no processo, na qualidade de substituto de certa coletividade de pessoas, seja capaz de efetivamente representar e proteger os interesses dessa coletividade.

Posto isso, pergunta-se: qual o meio para se aferir a adequação da representação? Aqui se encontra a maior diferença entre o sistema brasileiro e aquele que vigora nos EUA. Ao contrário do que se dá em nosso ordenamento jurídico, observa-se que a legitimação para as class actions é aferida pelo juiz no caso concreto. Trata-se do modelo ope judicis, ou seja, o modelo de análise judicial da representação. Conforme se verá adiante, a diferença 
entre os dois modelos também implica grande divergência quanto ao regramento do instituto da coisa julgada.

Por fim, uma observação se impõe. É comum que se diga, em estudos de teoria e história do Direito, que existem dois sistemas de direito diversos que vigoram ao redor do mundo. ${ }^{10}$ Trata dos sistemas do common law e do romano-germânico. Neste último, no qual está inserida a experiência jurídica brasileira, dá-se mais valor à sistematização positiva do direito, através do estabelecimento de leis e códigos. No common law ocorre o contrário. Através do stare decisis, o direito se estabelece judicialmente, por meios de decisões judiciais que vão se repetindo e, assim, fixando-lhe o sentido. É esse o sistema que vigora nos países de origem anglo-saxônica. Posto isso, parece evidente que o sistema ope judicis é, na verdade, um corolário dessa concepção judicializada do fenômeno jurídico. O modelo ope legis, por sua vez, representa a visão romano-germânica do direito.

Com isso não se quer dizer, porém, que os dois sistemas vivam isolados e, portanto, não possam estabelecer qualquer tipo de ligação. O que se observa nos dias de hoje, ao contrário, é que, cada vez mais, um sistema passa a incorporar características do outro. Tal fato, como se verá, irá nos auxiliar na busca por uma fundamentação para a defesa da possibilidade das ações coletivas passivas no sistema jurídico brasileiro.

\subsubsection{Legitimidade passiva para as ações coletivas no ordenamento brasileiro: a possibilidade de um modelo bifásico}

Conforme explicitado, no caso da legitimação ativa para as ações coletivas, o ordenamento jurídico brasileiro consagra o modelo ope legis, ou seja, a legitimação dá-se pela lei. Ante tal fato, questiona-se: se, portanto, a legitimação ativa se dá por força de lei; e se não há previsão legal que legitime coletividades a figurarem no polo passivo das ações coletivas, é correto dizer que tal não é possível no Direito brasileiro?

Com efeito, é essa a conclusão a que muitos doutrinadores chegam. Porém, defendemos aqui a posição oposta, ou seja, a de que a ação coletiva passiva é possível - e até necessária - na ordem jurídica de nosso país. Dito isso, devemos investigar como poderia ocorrer a aferição dessa legitimidade.

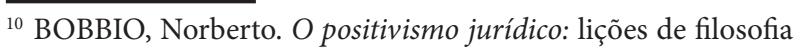
do direito. São Paulo: Ícone, 1995.
Tal poderia se dar mediante duas etapas. Na primeira delas, haveria a constatação da previsão legal da possibilidade de certas coletividades figurarem na demanda. Mas, como isso se faria possível, já que, conforme dito, não há previsão legal de legitimados passivos para as ações coletivas? Na verdade, deveria ser levado a efeito um argumento analógico, de acordo com o qual seriam considerados legitimados passivos aqueles que a lei prevê como legitimados ativos. A primeira das etapas, conforme se observa, nada mais é do que uma aplicação qualificada do já explicado modelo ope legis.

A segunda das etapas é que seria o diferencial da aferição da legitimidade passiva em relação à ativa nas ações coletivas. Nesse momento, deverá o juiz realizar o exame da representação in concreto, ou seja, deve ele aferir se o possível legitimado de fato representa a coletividade adequadamente naquele caso. No momento de tal avaliação deve o juiz ter em mente certos critérios, tais como a idoneidade e a popularidade do representante.

A vantagem desse modelo é latente. Com efeito, é comum que, em certas ocasiões, aconteça de uma entidade legalmente legitimada não representar, de fato, os interesses da coletividade. É esse o mal que a segunda etapa da aferição da legitimidade nas ações coletivas passivas busca remediar. Assim, deve o juiz, sempre que lhe parecer necessário, valer-se dos elementos mais variados - tais como a opinião de indivíduos pertencentes à coletividade que se está querendo representar - para concluir pela legitimidade de certo representante. Nesse sentido, é notável a contribuição que o modelo do common law nos fornece, à medida que afasta as formalidades que, por vezes, comprometem a efetividade do processo.

\subsection{Coisa julgada e as ações coletivas passivas}

Matéria de extrema relevância quando se trata de processo coletivo é a coisa julgada. De fato, as concepções a respeito desse instituto que permeiam o processo individual não são capazes de dar respostas efetivamente significativas para as controvérsias que envolvem as demandas coletivas. Assim sendo, algumas considerações devem ser feitas sobre o modo como a ideia de coisa julgada deve operar nesse contexto.

Como bem se sabe, a coisa julgada no âmbito dos processos individuais é regulada pelo artigo 472 do Código de Processo Civil, in verbis: "A sentença faz coisa julgada às partes entre as quais é dada, não beneficiando, 
nem prejudicando terceiros [...]". Tal regulamentação é exigência dos princípios do contraditório e da ampla defesa, que estabelecem que somente podem se sujeitar aos efeitos da sentença aqueles que participaram ativamente, defendendo seus interesses por todos os meios aceitáveis, no processo judicial.

Ocorre que, como já aludido, no processo coletivo, e em especial nas ações coletivas passivas, as consequências da exigência da coisa julgada não ficam muito claras. Aqueles que são representados nas ações coletivas devem sempre se sujeitar aos efeitos da sentença? Pelas peculiaridades que envolve, essa questão gera grandes discussões.

No intuito de resolvê-la, o Código de Defesa do Consumidor - diploma que atualmente regula, ao lado da Lei da Ação Civil Pública, as principais questões atinentes ao processo coletivo - trouxe alguns dispositivos a respeito da coisa julgada (arts. 103 e 104). Fixou a ideia de coisa julgada secundum eventum litis, ou seja, aquela cujos efeitos variam conforme o resultado do processo.

Antes de darmos continuidade, vale lembrar que essa ideia se harmoniza e é justificada em razão do regime de regulação da legitimidade nas ações coletivas. Conforme dito, a legitimidade ativa para essas ações coletivas vem prevista na lei, ou seja, o Estado estabelece uma presunção de que certas coletividades podem ser representadas por aqueles que ele legitimou. Assim sendo, nada mais lógico do que estabelecer que aqueles que são representados - ou, melhor dizendo, aqueles que o Estado pressupõe, por meio da lei, que estão representados - somente sofram os efeitos de certa decisão judicial caso ela lhes seja favorável.

No âmbito das ações coletivas ativas, a utilidade da previsão da coisa julgada secundum eventum litis é inegável, visto que, conforme se disse, a lei é que estabelece a legitimidade ativa para tais ações. Mas será que o mesmo se dá no âmbito da ação coletiva passiva, já que, como se disse, nela também deve haver - na segunda das etapas de averiguação da legitimidade - a aferição da representatividade adequada daquele que representa a coletividade?

A resposta é positiva. De fato, nada obsta a que seja aplicado tal regime às ações coletivas passivas. No direito norte-americano, especialmente em razão do fato de que a legitimidade, tanto ativa como passiva, somente é aferida pelo modelo ope judici adota-se regime diferente para a coisa julgada, operando ela erga omnes e inde- pendentemente do resultado do processo. Ocorre que tal solução, pelas razões já aventadas, não pode ser aplicada ao modelo brasileiro de ação coletiva passiva, já que é por meio da lei que a legitimidade para tais ações é, ainda que prima facie, fixada.

\section{Construindo um argumento}

\subsection{A constitucionalização do direito}

Tradicionalmente, o direito privado esteve no centro da ordem jurídica. Aliás, pode-se dizer que a ideia de ordenamento jurídico surge como consequência da intensa evolução operada especialmente no âmbito do Direito Civil. Ocorre que, desde meados do século XX, tal situação se alterou profundamente. De fato, pelas razões e com as consequências que a seguir serão abordadas, a Constituição - e, portanto, o Direito Constitucional passou a exercer grande protagonismo no cenário jurídico, condicionando a interpretação de todos os elementos normativos que ele contém.

Procurar-se-á evidenciar, partindo-se das ideias que as ocasionaram, as principais consequências, em especial aquelas que dizem respeito ao direito processual coletivo, de tal transformação.

\subsubsection{A força normativa da constituição}

$\mathrm{Na}$ Europa, até a primeira metade do século passado, a Constituição foi vista como um documento essencialmente político, "[...] um convite à atuação dos Poderes Públicos". ${ }^{11}$ Nesse período, as "normas" constitucionais não eram concebidas como elementos propriamente jurídicos, já que não possuíam força normativa.

A grande mudança de paradigma ocorreu logo após a Segunda Grande Guerra. Com efeito, nesse momento, operou-se ao redor do mundo uma grande onda de constitucionalização, ou seja, diversos países passaram a adotar constituições escritas. Nesse contexto, passou-se a aceitar a ideia de obrigatoriedade dos enunciados constitucionais, quer dizer, ganhou força a visão de que "[...] as normas constitucionais são dotadas de imperatividade, que é atributo de todas as normas jurídicas, e sua inobser-

${ }^{11}$ BARROSO, Luis Roberto. Curso de direito constitucional contemporâneo: os conceitos fundamentais e a construção do novo modelo. São Paulo: Saraiva, 2009. p. 262. 
vância há de deflagrar os mecanismos próprios de coação, de cumprimento forçado". ${ }^{12}$

Deve-se observar que o desenvolvimento de tal doutrina nos países em geral e em especial no Brasil, vai de encontro a uma série de práticas até então arraigadas em nossas instituições. De fato, pode-se dizer que a Constituição usualmente foi vista como um "repositório de promessas vagas", ${ }^{13}$ ou seja, como um conjunto de afirmações que, distantes da realidade, serviam apenas de norte à atividade do poder político. "Coube à Constituição de 1988, bem como à doutrina e à jurisprudência que se produziram a partir de sua promulgação, o mérito elevado de romper com a posição mais retrógrada”. ${ }^{14}$

A ideia de força normativa da Constituição ${ }^{15}$ é ainda corroborada pelos mais diversos instrumentos de efetivação do Direito Constitucional. Veja-se, por exemplo, o grande desenvolvimento operado ao redor do mundo nos mecanismos de controle de constitucionalidade, ou seja, de verificação da compatibilidade dos diversos dispositivos normativos com a Constituição. De fato, a razão de ser de tal controle é a concepção de que a Constituição é norma imperativa, e, portanto, não pode ser por qualquer meio desrespeitada.

Posto tudo isso, torna-se claro que a ideia de constitucionalização - que fundamenta a exigibilidade da ação coletiva passiva - tem como antecedente lógico a noção de força normativa da Constituição.

\subsubsection{Centralidade da constituição na ordem jurídica}

Como consequência do fenômeno da normatividade da Constituição, e dando substância àquilo que chamamos de constitucionalização, observa-se que o documento constitucional passou a ocupar papel central na resolução de todas as questões que envolvem qualquer elemento de um ordenamento jurídico.

Essa centralidade da Constituição, e em especial de sua parte dogmática, ${ }^{16}$ opera-se de duas formas. De

\footnotetext{
${ }^{12}$ BARROSO, Luis Roberto. Curso de direito constitucional contemporâneo: os conceitos fundamentais e a construção do novo modelo. São Paulo: Saraiva, 2009. p. 263.

${ }^{13}$ Ibidem, p. 263.

${ }^{14}$ Ibidem, p. 263.

${ }^{15}$ HESSE, Konrad. Temas fundamentais do direito constitucional. São Paulo: Saraiva, 2009.

${ }^{16}$ COELHO, Inocêncio Mártires. Interpretação constitucional. São Paulo: Saraiva, 2007.
}

acordo com a primeira delas, aceita-se que as cláusulas constitucionais, em razão de sua força normativa, outorgam direitos aos indivíduos de forma direta, criando assim uma série de prerrogativas que devem ser garantidas e respeitadas pelo poder público.

Deve-se observar que, antes do advento da noção de força normativa da Constituição, não se aceitava que a Constituição reconhecesse, sem intermédio de outra instituição, quaisquer direitos efetivamente exercitáveis. Conforme se disse, ela era vista como um convite à atuação do poder político e, por essa razão, não atribuía prerrogativas de forma direta.

O segundo sentido da centralidade da Constituição é um tanto mais complexo. Desenvolveu-se principalmente por influência de decisões do Tribunal Constitucional alemão. Nesse segundo sentido, a Constituição é vista não como uma declaração de direitos, mas sim como uma ordem objetiva de valores que lança luz a todo o ordenamento jurídico. É justamente por força dessa compreensão que se diz que a Constituição, nos tempos atuais, condiciona a leitura de todo o direito de um país, ou seja, toda interpretação jurídica deve ser, antes de tudo, uma interpretação da Constituição, já que tudo que se realiza no ordenamento jurídico deve estar em compatibilidade com ela.

O fenômeno da constitucionalização pode ser visto como causa e consequência dessas duas dimensões da centralidade. De fato, a separação das duas ideias somente se faz possível no plano abstrato e sua utilidade é meramente didática.

\subsubsection{Ativismo judicial vs. moderação judicial}

Ante as ideias já referidas, duas posturas diametralmente opostas se colocaram no âmbito da justiça constitucional. De fato, a grande questão aqui diz respeito à efetivação das chamadas cláusulas constitucionais vagas. ${ }^{17}$

Tais cláusulas, a exemplo daquelas que estabelecem o direito à liberdade e à igualdade, impõe relevantes desafios aos aplicadores dos direitos. Ante a vagueza que lhes é inerente, como fixar-lhes o sentido? Como dito, duas vertentes surgiram com respostas diferentes para essa questão.

\footnotetext{
${ }^{17}$ DWORKIN, Ronald. Levando os direitos a sério. São Paulo: WMF M. Fontes, 2010.
} 
Para a primeira delas, a moderação judicial, o juiz, quando se vê diante de alguma cláusula vaga, deve abster-se de formular as concepções que lhe parecem ser as melhores para a resolução dos casos que lhes são submetidos. O julgador, portanto, deve atuar apenas com base naquilo que foi estabelecido por outros poderes que não o judiciário - em geral, pela legislatura -, não devendo exercer qualquer função criativa.

Sustentada pelo princípio democrático das decisões majoritárias, a doutrina da moderação teve grande influencia no estudo do Direito Constitucional. ${ }^{18}$ Ocorre que, passada a primeira metade do século XX, e por influência de diversas decisões proferidas pelo Tribunal Constitucional dos Estados Unidos da América ao longo das décadas de 1950 e 1960, essa doutrina tem cedido espaço ao ativismo judicial.

Para os ativistas, quando os juízes se deparam com casos em que são aplicáveis algumas cláusulas constitucionais vagas - casos que, no dizer de Hart, estão no âmbito da textura aberta do direito ${ }^{19}$-, deve ele, argumentativamente, construir o sentido concreto de tais cláusulas.

Dworkin, ${ }^{20}$ defensor de tal ponto de vista, entende que dar efetividade, ou seja, fazer cumprir a Constituição é atuar ativamente na concretização dos conceitos vagos positivados pelo constituinte. Para esse autor, ao contrário do que dizem diversos críticos do ativismo, aqueles que se pautam pela doutrina da moderação negam o caráter impositivo da Constituição, já que seria da própria essência desse ramo do direito a necessidade da concretização judicial de enunciados vagos.

É dessa ideia exposta por Dworkin que se parte para a elaboração do presente argumento. Não se pode imaginar, dadas as já explicitadas ideias de constitucionalização e força normativa da Constituição, que os enunciados normativos constitucionais tenham sua concretização condicionada a qualquer atuação de outra instituição, que não o poder judiciário. Admitir-se uma postura como essa é negar a enorme evolução pela qual passou a dogmática constitucional.

${ }^{18}$ WALDRON, Jeremy. A dignidade da legislação. São Paulo: M. Fontes, 2003.

${ }^{19}$ HART, H. L. A. O conceito de direito. São Paulo: WMF M. Fontes, 2009. p. 161-175.

\subsubsection{Enunciados constitucionais aplicáveis}

Ante todas essas ideias, pergunta-se: quais são os dispositivos constitucionais capazes de fundamentar a admissão da ação coletiva passiva? São eles, basicamente, dois: a garantia do acesso à justiça, prevista no artigo $5^{\circ}$, inciso XXXV da Constituição Federal; e a cláusula do devido processo legal, prevista no inciso LIV do artigo citado. Vejamos, em linhas gerais, em que consiste cada uma das ideias.

Nos termos do inciso XXXV do artigo $5^{\circ} \mathrm{da} \mathrm{CF}$, “[...] a lei não excluirá da apreciação do Poder Judiciário lesão ou ameaça a direito". Tal garantia - usualmente referida como garantia do acesso à justiça ou princípio da inafastabilidade do controle jurisdicional - veda que qualquer direito permaneça sem proteção judicial, e, portanto, obriga o Estado a criar os mais diversos meios para que os cidadãos, individual ou coletivamente, dirijam-se ao judiciário para requerer a proteção de seus interesses.

Ora, no caso da ação coletiva passiva, sua admissão é meio de se levar a juízo questões que envolvem potenciais lesões a direitos. Assim sendo, pode-se dizer, de fato, que sua inadmissão terá por consequência óbvia a negativa de proteção de direitos que, pertencendo a uma coletividade, dificilmente seriam levados ao judiciário por meio de demandas individuais. É esclarecedor, nesse sentido, a seguinte passagem da obra de José Afonso da Silva:

[...] (a garantia do acesso à justiça) consiste no direito de invocar a atividade jurisdicional sempre que se tenha como lesado ou simplesmente ameaçado um direito, individual ou não, pois a Constituição já não mais o qualifica de individual, no que andou bem, porquanto a interpretação sempre fora a de que o texto anterior já amparava direitos, p.ex., de pessoas jurídicas ou de outras instituições ou entidades não individuais, e agora hão de levar-se em conta os direitos coletivos também. ${ }^{21}$

No que diz respeito à ideia de devido processo legal, vem ela exposta no inciso LIV do mesmo artigo $5^{\circ} \mathrm{da} C F$, in verbis: "[...] ninguém será privado da liberdade ou de seus bens sem o devido processo legal”. Tal enunciado não está a indicar apenas a necessidade de que sejam disponibilizados procedimentos adequados à proteção dos direitos; na verdade, ele vai além disso. Quer indicar a obrigatoriedade da existência de um arranjo institucional capaz de proporcionar aos sujeitos processuais o exercício de todas as ativi-

${ }^{21}$ SILVA, José Afonso da. Curso de direito constitucional positivo. 30. ed. São Paulo: Malheiros, 2008. p. 431. 
dades imagináveis - desde que não sejam contrárias ao direito, logicamente - para a defesa de seus direitos em juízo. Com essa garantia se relacionam várias outras, tais como a exigência de contraditório e a plenitude de defesa, previstas no inciso LV do artigo $5^{\circ}$ da Constituição Federal.

Desta superficial explicação, já se pode extrair a ideia de que a cláusula do devido processo legal está a exigir a admissão da ação coletiva passiva. Isso porque, conforme dito, ela torna imperativa a disponibilização dos mais diversos meios para a defesa dos diretos dos cidadãos, e, como se sabe, a ação coletiva passiva é, inegavelmente, um deles.

\subsection{Mais uma vez, a instrumentalização do processo}

Até aqui se buscou esclarecer como se dá - ou como deveria se dar - a inserção dos valores constitucionais nos mais diversos ramos do direito. Ocorre que tal fenômeno é mais claro quando se fala dos ramos de direito material. Quando tratamos de processo, pode parecer - ainda mais se se tem em mente a já ultrapassada ideia de autonomia absoluta do processo - que as regras processuais não possuem qualquer dimensão axiológica, e, portanto, não se faz relevante a reflexão a respeito do fenômeno da constitucionalização do âmbito processual.

Tal pensamento é de todo equivocado. Conforme já se disse, vivemos hoje a terceira fase metodológica do direito processual, a fase instrumental. Não mais se concebe que o direito processual possa permanecer neutro, ou seja, apartado do direito substancial. Deve ele ser visto como um instrumento ético, no sentido de que "a regulamentação do processo depende basicamente de concepções filosóficas, políticas e culturais inerentes ao direito material. Daí ser insuficiente o formalismo dogmático, que deve ser complementado pela ideia de valor" ${ }^{22}$

Posto isso, fica claro que a ideia de instrumentalidade, assim como fez com que o processo se adaptasse às transformações geradas pelas diversas gerações dos direitos, também obriga o surgimento de novas concepções que sejam capazes de dar concretude à mencionada ideia de constitucionalização do direito.

\subsection{Ação coletiva passiva, um imperativo}

É chegada a hora de concluirmos o raciocínio. Retomemos antes algumas premissas. Conforme dito, por constitucionalização do direito se compreende o fato de que a Constituição passou a desempenhar papel central na ordem jurídica. Com isso se quer dizer que todo o direito deve ser lido e compreendido à luz dos valores constitucionais. Ao se dar forma a tais afirmações, encontra-se a ideia de força normativa da Constituição. De fato, as normas constitucionais são normas jurídicas,e, portanto, imperativas. Nesse sentido, não mais podem existir razões para se limitar a efetividade do direito constitucional.

A par disso, emerge o problema das cláusulas constitucionais vagas, tais como aquelas que consagram o direito à liberdade e igualdade. Ante tal fato, questiona-se qual deve ser a postura do juiz, quando da aplicação de tais enunciados. Buscou-se mostrar que deve ele, adotando uma postura ativista, formular concepções que dão sentido concreto e efetivo a tais cláusulas.

A partir dessas premissas, podemos levar adiante o seguinte raciocínio: a garantia do acesso à justiça e o direito ao devido processo legal fazem parte da Constituição e, portanto, compõe aquilo que chamamos de conjunto objetivo de valores constitucionais. À luz da ideia de constitucionalização, tais valores hão de se irradiar por todo o ordenamento jurídico e, assim sendo, orientar a interpretação de todas as normas jurídicas.

Isso posto, e tendo em vista a crucial ideia da instrumentalidade do processo - que impõe a necessidade de que o processo se contamine e dê efetividade aos valores do direito substancial, abandonando, assim, qualquer ideia de neutralidade - conclui-se que as duas cláusulas constitucionais citadas - e, com base na ideia de constitucionalização, o ordenamento jurídico como um todo - exigem a admissão da ação coletiva passiva.

No mais, deve-se observar que tanto a garantia do acesso à justiça quanto o devido processo legal são cláusulas constitucionais vagas. Conforme já se disse, devem elas ser concretizadas, ou seja, densificadas pelo aplicador do direito. Por certo, no exercício de tal atividade, não goza o juiz de poder discricionário. Pelo contrário, todo o seu raciocínio deve, a todo o momento, referir-se a outros elementos normativos, ${ }^{23}$ de modo que o ideal de consistência

\footnotetext{
${ }^{23}$ DWORKIN, Ronald. O império do direito. São Paulo: WMF M. Fontes, 2010. p. 213-270.
} 
- exigência muito mais forte que a simples coerência ${ }^{24}$ condicione e dê forma a toda a sua atuação.

Assim, portanto, tal itinerário nos levará, inexoravelmente, à conclusão de que deve ser admitida a ação coletiva passiva. Isso porque tal conclusão é uma exigência de consistência; ou seja, o ordenamento jurídico, compreendido em toda sua complexidade, impõe tal solução.

\section{Conclusão}

Conforme se tentou demonstrar, a relevância e a utilidade do estudo do processo coletivo advêm da grande mudança operada no âmbito do direito material. Tal mudança, que está implícita na evolução e no surgimento das diversas gerações dos direitos, apresenta novos desafios que somente podem ser superados com a criação de novos instrumentos adequados para tal. A ação coletiva passiva é um desses instrumentos. Com efeito, apresenta-se ela como uma inafastável exigência do arranjo jurídico brasileiro e, em especia, da garantia de acesso à justiça e do direito ao devido processo legal, ambos garantidos a nível constitucional.

No que diz respeito aos aspectos processuais mais controvertidos atinentes à matéria, ficou clara a possibilidade de se harmonizarem os conceitos de legitimidade e de coisa julgada já consagrados com as novas exigências colocadas pela ação coletiva passiva. De fato, ao sistema ope legis - difundido no ordenamento brasileiro - deve se somar a ideia de representatividade adequada, de modo a garantir que a coletividade demandada tenha, de fato, seus direitos protegidos. Quanto à coisa julgada, já foi dito, a variação de seus efeitos secundum eventum litis é meio hábil à garantia do contraditório e da ampla defesa, não se afigurando correto dizer que tal ideia poderia retirar toda a utilidade da ação coletiva passiva.

Quanto ao mais, devemos reiterar a exigência de que os tribunais enfrentem a questão que ora se discute. De fato, o que se observa é que - tanto nos casos em que se admite, quanto naqueles em que se nega a possibilidade da ação coletiva passiva - os julgadores sequer abordam a matéria, o que está a revelar a falta de percepção, por parte daqueles que operam o direito, da atualidade e utilidade do tema.

\section{Referências}

BARROSO, Luis Roberto. Curso de direito constitucional contemporâneo: os conceitos fundamentais e a construção do novo modelo. São Paulo: Saraiva, 2009.

BEDAQUE, José Roberto dos Santos. Direito e processo. 5. ed. São Paulo: Malheiros, 2009.

BENJAMIN, Antônio Herman V.; MARQUES, Claudia Lima; BESSA, Leonardo Roscoe. Manual de direito do consumidor. 3. ed. rev. atual. e ampl. São Paulo: Revista dos Tribunais, 2010.

BOBBIO, Norberto. A era dos direitos. Trad. de Carlos Nelson Coutinho. Rio de Janeiro: Campus, 1992.

BOBBIO, Norberto. O positivismo jurídico: lições de filosofia do direito. São Paulo: Ícone, 1995.

CINTRA, Antonio Carlos de Araújo; GRINOVER, Ada Pellegrini; DINAMARCO, Cândido Rangel. Teoria geral do processo. 24. ed. São Paulo: Malheiros, 2008.

COELHO, Inocêncio Mártires. Interpretação constitucional. 3. ed. São Paulo: Saraiva, 2007.

DWORKIN, Ronald. Levando os direitos a sério. Trad. Nelson Boeira. 3. ed. São Paulo: WMF Martins Fontes, 2010 .

DWORKIN, Ronald. O império do direito. Trad. Jefferson L. Camargo. São Paulo: Martins fontes, 2007.

GUEST, Stephen. Ronald Dworkin. Trad. Luís Carlos Borges. Rio de Janeiro: Elsevier, 2010.

HART, H. L. A. O conceito de direito. Trad. Antônio de Oliveira Sette-Câmara. São Paulo: WMF Martins Fontes, 2009.

HESSE, Konrad. Temas fundamentais do direito constitucional. Textos selecionados e traduzidos por Carlos dos Santos Almeida, Gilmar Ferreira Mendes, Inocêncio Mártires Coelho. São Paulo: Saraiva, 2009.

SILVA, José Afonso da. Curso de direito constitucional positivo. 30. ed. São Paulo: Malheiros, 2008.

WALDRON, Jeremy. A dignidade da legislação. Trad. Luís Carlos Borges; revisão da tradução Marina Appenzeller. São Paulo: M. Fontes, 2003. 